\title{
Literatura CONTEMPORÂNEA E CAMPO EXPANSIVO: A ENCENAÇão da LINGUAGEM EM VERONICA STIGGER
}

\section{CONTEMPORARY LITERATURE AND THE EXPANSIVE FIELD: A PERFORMANCE OF LANGUAGE IN VERONICA STIGGER}

\author{
Nilcéia Valdati ${ }^{1}$, Fernanda Motter $^{2}$
}

\begin{abstract}
Resumo: A partir dos desdobramentos da noção de campo expansivo, de Rosalind Krauss (1979), que chegam até Garramuño (2009), Brizuela (2014), Cámara e Aguilar (2017) e Klinger (2008), observamos como a criação artística de Veronica Stigger expande o campo literário para se encontrar com elementos das artes visuais, do teatro, do cinema. Em Os anões (2010a), Stigger brinca com as regras, mantendo seu teor irônico e imprevisível. Com um cotidiano distorcido, vai rompendo gênero e linguagem. Em Opisanie Swiata (2013), o leitor é colocado diante de uma experiência em um experimento poético narrativo, por meio de um objeto extremamente sedutor composto por cartas geográficas, fotografias, cartões postais, anúncios publicitários, cardápios, cartas pessoais e uma narrativa carregada de referências a personagens, autores e obras do modernismo brasileiro numa viagem da Polônia à Amazônia. Interessa-nos perceber como o processo de criação de Stigger nesses trabalhos ocorre por meio de uma encenação da linguagem.
\end{abstract}

Palavras-chave: Campo expansivo; Veronica Stigger; encenação da linguagem.

Abstract: Working off the ramifications of the notion of expansive field by Rosalind Krauss (1979) that later reaches Garramuño (2009), Brizuela (2014), Cámara and Aguilar (2017) and Klinger (2008), we observe how the artistic endeavor in Veronica Stigger expands the literary field to meet elements of the visual arts, theater, and cinema. In Os anões (2010), Stigger plays around with the rules and keeps her ironic and unpredictable tone. Through a distorted depiction of daily life, she goes about disrupting genre and language. In Opisanie Swiata (2013), the reader is confronted with an experimental poetic narrative through the seductive use of geographic letters, photographs, postal cards, ads, menus, personal letters, and a narrative brimming with references to characters, authors and works belonging to Brazilian modernism, all in a trip from Poland to the Amazon. Our interest lies in observing how Stigger's creative process, in these works, goes through a performance of language.

Key words: Expansive field; Veronica Stigger; performance of language

\section{Introdução}

Em 2009, Florência Garramuño publica "La literatura en un campo expansivo: y la indisciplina del comparatismo" pelos Cadernos de Estudos Culturais, número dedidicado à

\footnotetext{
${ }^{1}$ Professora de Literatura Brasileira, no Departamento de Letras da Unicentro.

${ }^{2}$ Mestranda do Programa do Pós-graduação em Letras da Unicentro.
} 
discussões sobre a literatura comparada, republicado no Brasil, em 2014, no livro Frutos estranhos, cujo subtítulo aposta numa leitura e categorização para uma parte da produção contemporânea, qual seja, "sobre a inespecificidade na estética contemporânea".

Garramuño inicialmente lembra as considerações de Rosalind Krauss (1979) em relação ao pensar a escultura num campo expansivo a fim de "situar o aparecimento de um novo tipo de obras artísticas que só podiam continuar a ser consideradas como esculturas se a própria categoria se expandisse até se tornar uma categoria infinitamente maleável" (GARRAMUÑO, 2014, p.33). Para, posteriormente, levar a noção de campo expansivo para a literatura, neste sentido coloca-a lado a lado com a ideia de literatura fora de si, indo além da possibilidade de traçar uma genealogia de quando a literatura tentou sair de si. Interessa a pesquisadora argentina centrar-se no "transbordamento sistemático desses limites" em textos que considera os mais interessantes da literatura contemporânea e analisar como esse desdordamento tem enquanto "consequência um pôr em xeque algumas definições muito formalistas do literário e da estética”. (GARRAMUNO, 2014, p.34)

O pensamento de Garramuño ${ }^{3}$ encontra consonância com outros pesquisadores contemporâneos. Com o crítico paraguaio Ticio Escobar em El arte fuera de si (2004) amplia o conceito "fora de si"; com os conterrâneos argentinos Natália Brizuela em Depois da fotografia (2014), Gonzalo Aguilar e Mario Câmara com A máquina performática (2017) e Diana Klinger (2008), “A escrita de si como performance”, estabelece um diálogo sobre a força da literatura experimental e a expansão do campo literário.

Nesse cenário da literatura latino americana "fora de si" podemos colocar em cena $O S$ anões (2010a) e Opisanie Swiata (2013) de Veronica Stigger. Neles, a autora cria condições para o surgimento de um ritmo de leitura em meio às rupturas e utiliza também, recursos como, rascunhos, bilhetes, conversas casuais e citações para ampliar a gama de sentidos e dialogar, a partir de outros formatos com o leitor. Porém, mesmo com tantas diferenciações em seus escritos, é possível envolver o trabalho de Veronica Stigger em um processo de criação experimental, por meio de elementos que compõem as artes como um todo. Sendo

\footnotetext{
${ }^{3}$ Um outro trabalho recente que coloca duplamente a expansão em evidência é a publicação de Indicionário do contemporâneo (2018), que além de discutir o tema pontualmente no "verbete" "Práticas inespecíficas", apresenta uma composição que já se coloca como uma atitude de insubordinação. O livro é composto por seis verbetes (além do já citado podemos encontrar arquivo, comunidade, endereçamento, o contemporâneo, pós-autonomia) escritos conjuntamente por quatorze ensaístas-pesquisadores-professores de diferentes universidades da América do Sul, sem identificação de autoria nos verbetes. O germe, que é plantado em 2012, num primeiro encontro do grupo, se estende para outros eventos e a publicação ocorre em 2018. Florência Garramuño, Diana Klinger e Mario Camara participam deste projeto coletivo.
} 
assim, alguns temas entre contos, minicontos e até mesmo em seu único autodenominado romance vão se aproximando, em relação ao movimento de escrita. O trágico, o cômico, o sarcasmo, o nonsense, a violência compõem um conjunto de elementos que acompanham Veronica Stigger em seu processo de criação que denominamos "encenação da linguagem". Conceito que associamos ao de performance, que seria praticamente um sinônimo para a língua inglesa, ou seja atuação, desempenho, rendimento. No entanto, procuramos colocar a encenação ou performance em outro estatuto, que possa questionar exatamente esta condição.

Diana Klinger (2008, p.19) fará um apanhado do uso do termo. Observa que a partir dos anos 1950, performance passou assumir nas artes e nas ciências humanas uma noção capaz de superar a dicotomia arte/vida, pois de maneira geral, seria toda a atividade realizada por um indivíduo ou grupo, que revelaria o caráter genuíno e individual de uma cultura. Entretanto, adverte que ao contrário disso, "o performático significa, na teoria de gênero da crítica norte-americana Judith Butler, não o 'real, genuíno', mas exatamente o oposto: a artificialidade, a encenação". Eis o ponto que desejamos ler na produção artística de Verônica Stigger: a encenação, ou a performance, como artificialidade.

\section{A encenação de um livro}

Os anões, livro de Veronica Stigger, publicado em 2010 pela editora Cosac Naify apresenta aos leitores contos, minicontos e dois contos-roteiro. Ao todo, são 21 textos, divididos entre pré-histórias, histórias e histórias de arte. Ao fazer essa separação, Stigger (2010a), enquanto leitora, explora muitas de suas referências, como Flávio de Carvalho, João Cabral, Maria Martins e Carlos Drummond de Andrade e as integra ao livro enquanto escritora. Além de arte, a autora explora seu "olho-jorro", tomando o conceito de Didi-Hubermann (2012), deixando a imaginação fluir, como é o caso de conversas de rua, diálogos com seus amigos, frases e imagens soltas, que são gatilhos que Veronica usa para escrever seus textos.

Ao pensar em anões, cria-se uma imagem de um corpo pequeno e atarracado. Com 60 páginas em papel cartonado, grosso e que mede $16 \mathrm{~cm}$ de altura e $12 \mathrm{~cm}$ de largura atribui-se as formas do livro à concepção conceitual da palavra. Trata-se de um "livro anão" em que numa mistura de gêneros, Veronica Stigger brinca com os estatutos normativos, mantendo um teor irônico e imprevisível a cada página lida. Com um cotidiano distorcido a escritora vai 
rompendo padrões tanto nas ações dos personagens, bem como na estética e linguagem. Os anões talvez seja o livro de Stigger em que o absurdo mais aparece, despertando no leitor a reflexão sobre as ferramentas de composição.

Durante a leitura encontram-se caixas com as bordas arredondadas em vários formatos, sempre na cor preta. São páginas que se apresentam somente enquanto espaços vazios, como se fosse responsabilidade do leitor preenchê-los. Diante disso, é possível refletir sobre a literatura contemporânea, pois ao nos depararmos com narrativas fragmentadas de cunho artístico e político, a leitura torna-se uma experiência, manifestando diversas sensações no leitor-espectador.

Essas sensações que começam pelo tato, de um leitor que sente o livro ao manuseá-lo, são também exploradas no brilho, na textura e na espessura das páginas, usando apenas as cores preta e branca. De acordo com Damásio Marques da Silva (2017) em seu artigo "Os anões: o papel do leitor na literatura de Veronica Stigger", a experiência começa a partir da corporeidade do objeto, na interação entre o espaço do livro, do seu corpo mesmo, da materialidade tátil e as expansões, percepções e sensações que podem trazer o livro e o texto, antes mesmo de abri-lo.

[...] Um espetáculo visual que, antes mesmo da leitura do código linguístico, lança o olhar do leitor às páginas negras iniciais e finais, e às tarjas negras que refletem a imagem do leitor como num espelho, evidenciando a obrigatoriedade de sua participação como um coautor da obra. (SILVA, 2017, p.166)

Em entrevista, Stigger (2010b) reafirma sua preferência por minicontos e formatos curtos. "A escolha por formas curtas, em alguns casos tão curtas e tão rápidas me parecem funcionar como uma lufada inesperada de ar que golpeia o rosto do leitor e o deixa sem saber o que, afinal, acaba de acontecer". A lufada, que Stigger se refere é uma metáfora do boxe, em que o romance é como uma luta em que se vence por pontos e o conto é aquele em que o oponente é derrotado por nocaute, o miniconto seria a luta em que se vence por nocaute e no início do primeiro assalto.

Segundo Gustavo Ramos de Souza (2016), em “O espetáculo em minicontos de os anões, de Veronica Stigger”, isso acontece a partir da brevidade intrínseca a esse gênero, pois não há sequer espaço para que se desenvolva a tensão que é característica do conto, sendo que o conteúdo está tão condensado que nem mesmo uma vírgula pode ser gratuita. 
Imerso a cotidianos absurdos, Stigger (2010a) tem a capacidade de usar aquilo que já foi dito, percebendo as piadas e acrescentando em seu texto, fazendo com que seja gerado uma comicidade através do absurdo e da falta de sentidos. Em Os anões, vê-se uma interação com as artes visuais e outras artes, expandindo o texto literário em direção a essas artes. Conforme nos propõe Gonzalo Aguilar e Mario Cámara (2017), o campo literário passa a ser pensado como um campo expandido, ou seja, no qual está implicado o corpo, a voz e o espaço em instâncias menores que pouco são vistas pela crítica tradicional. Portanto, esse campo experimental se transforma em diferentes matérias e signos.

O conceito de performance que permeia as discussões de Aguilar e Cámara (2017) tem o sentido na enunciação, que, muitas vezes, atua no deslocamento de referências, lugares, significados ou práticas. Sendo assim, os autores estão preocupados em estudar a constituição em ato de uma prática da literatura não literária, isto é, não sujeita a enquadramentos e limitações da palavra escrita.

A partir da performance, surge o que Aguilar e Cámara (2017) chamam de “dispositivos performáticos”. Estes, são colocados como práticas atreladas a um regime em que as correspondências ainda estão por se estabelecer e assumem a tarefa de aprofundar-se nas práticas acessórias ou consideradas menores, as quais envolvem um certo objeto artístico, alterando o seu estado originário.

A literatura de Veronica Stigger em muitos momentos, como em Os anões, apresenta seu caráter político, ligando-se ao corpo através da linguagem. O jogo político de Stigger (2010a) tem relação com uma textualidade incorpórea, que altera as expectativas em torno do literário. Para Aguilar e Cámara (2017) a política atua e determina as condições e práticas sobre o corpo, seja ele social, próprio, coletivo ou imaginário, problematizando a ideia de corpo autônomo e inviolável.

Didi-Huberman (2012) em A pintura encarnada nos apresenta o conceito de “olho-jorro". Ele nos propõe pensar no pintor (e nós elevamos as discussões ao escritor, ou ao artista) e na sapiência que, em outras palavras, é um grande acervo de conhecimento, fatal quando o mesmo muda seu humor, ou sua forma de criar, já que suas produções são antes de tudo "um paradigma histórico, que nos conta também a louca projeção do humor (o líquido colorido) sobre um pincel que lhe fornece figura" (DIDI-HUBERMAN, 2012, p.20). Essa projeção feita pelo autor, refere-se ao jorro, capaz de propiciar um tempo de pausa na sequência, seja ela da pintura ou literatura. O olho-jorro, portanto, se pauta na questão da 
partilha e arbitragem ainda "às cegas". Didi-Huberman transfere seu pensamento para uma "ereção do olho", que também acontece através da demanda do humor.

\begin{abstract}
Imagino, antes, uma exorbitância, isto é, propriamente uma ereção do olho: sua vocação a dar golpes, golpes que o imponente pincel ainda não sabe desferir. $E$ isso passa justamente por uma demanda de humor. O olho injeta-se de sangue. Imagino o branco do olho de Apeles injetado do mesmo sangue que aquele de sua esponja, e imagino que é também por isso que a branca baba do cavalo representado finalmente misturava ali tão bem seus filetes de sangue [...] E isso era 'a vida' que faltava no quadro: uma mistura reticulada, uma fibrina, improjetável (no sentido do projeto), unicamente 'jetável', de humores brancos e vermelhos. (DIDI-HUBERMAN, 2012, p.21).
\end{abstract}

Didi-Huberman (2012) retoma um episódio de Cézanniano, em Gasquet, no qual justamente se conjugam dois possíveis motivos: a medida calculável e temporal dos golpes de pincel; o olho que toca, injetado de sangue. E ainda, esses motivos estão intimamente ligados a um terceiro, que o autor chama de "loucura".

Entre tantas características presentes nos textos de Stigger (2010a) a capacidade que a autora tem de perceber uma piada ou um gesto cômico e acrescentar em seus textos chama a atenção. Porém, em cenários completamente diferentes dos que ela viu ou ouviu, cria cotidianos cheios de absurdos, que resultam em uma comicidade.

Em muitos momentos, o absurdo pode chamar mais a atenção. Mas, como Stigger (2010a) carrega traços considerados próprios, fazendo referência a outros artistas, escritores e poetas, que com o seu gesto irônico faz de uma simples conversa nas ruas um conto ou um miniconto com uma intenção, de fazer a literatura um gesto de criação, um gesto político. Sendo assim, ao utilizar o conceito de corpo enquanto performance de Aguilar e Cámara (2017) observa-se de que forma Stigger (2010a) faz um deslocamento, seja das artes visuais ou da literatura.

E assim, Veronica vai traçando percursos ao longo do livro, mesclando suas chamadas "Pré-Histórias", "Histórias" e "Histórias da Arte". Com Flávio de Carvalho, por exemplo, Stigger (2010a) lança "Caverna", que tem como tema central a moda. Posteriormente, o livro apresenta o miniconto chamado "(Flávio de Carvalho)", novamente apropriando-se de textos prontos e inserindo-os em conjunto com Flávio de Carvalho.

New Color

(Utilicity 13,90$)$

Lâmina de aço inox 
Stigger (2010a) utiliza os nomes dos atores que figuram, portanto, apenas como nomes de edifícios colocados à venda, o que reduz a indicação entre parênteses e assim, de forma marginal. Dos autores, que situados nesse contexto, limitam-se à condição de um produto com valor mercadológico. Por assim dizer, a articulação feita por Stigger (2010a) está dentro e fora do literário.

A articulação de texto, imagem e artefato, em Os anões, cria uma rede de
'palabras, imágenes y movimentos; instrumentos para pensar, y también para
imaginar y producir afecciones' (LUDMER, 2010, p. 1), inscrevendo-se,
deste modo, no âmbito do que Herrero (2017) chama de 'artefatos de
profanar', que se materializam por meio de uma (re)ativação do improdutivo. (ALVES, 2018, p. 13)

E esse estar dentro e fora que o livro Os anões oferece a seus leitores faz parte de um livro estranho. Os quadros negros que aparecem no decorrer da leitura apontam para o espessamento da linguagem, que dialoga com o teatro. Por exemplo, as cortinas que se abrem ou que se fecham para dar lugar à encenação de dramas individuais e também no cinema, onde os quadros negros podem ser lidos como telas que convocam o leitor o tempo todo.

Outra convocação é o texto intitulado "Imagem verdadeira". Nele, Veronica apresenta sua suposta certidão de nascimento: “[...] VERÔNICA ANTONINE STIGGER, ocorrido no dia vinte e dois (22) de janeiro de mil novecentos e setenta e três (1973), nesta capital; de cor branca. Sexo masculino [...]" (STIGGER, 2010, p.57). Veronica é descrita em sua certidão como "sexo masculino". E, além disso, aproveita para instigar o leitor a duvidar, novamente colocando na corda bamba o pacto ficcional e estabelecendo novamente conexões entre o real, ou seja, um documento é ressignificado, mostrando o caráter cômico e ardiloso da escritora.

Em "Imagem verdadeira", Stigger (2010a) estabelece um contrato ficcional com os seus leitores, abrindo a possibilidade da aceitação imediata, da não aceitação ou da aceitação pausada sobre as informações, como um constante esconder-se, provocando o leitor a procurar algo. Veronica causa no leitor uma espécie de desconforto, que faz com que ele seja motivado a investigar e a pensar como e por qual motivo determinada informação está no texto e, em certa altura, entender tudo como parte de um quebra-cabeça que jamais será montado. Mas, talvez não seja possível dar uma resposta adequada. Uma suposição é a de que Stigger (2010a) faz da piada pronta um novo texto, questionando até mesmo a autoficção, ao 
entrar no mundo ficcional, deixa de ser verdade e passa a ter novas significações. Como nos lembra Klinger (2008, p.20), “[...] a autoficção também não pressupõe a existência de um sujeito prévio, 'um modelo', que o texto pode copiar ou trair, como no caso da autobiografia. Não existe original e cópia, apenas construção simultânea (no texto e na vida) de uma figura teatral - um personagem - que é o autor."

Ao incluir no livro uma certidão de nascimento, ou seja, um experimento fotográfico, coloca em xeque o que realmente um documento é. Portanto, a individualidade, a impessoalidade e a performance produzem, o que Florência Garramuño (2009) chama de uma forma de vida na cultura contemporânea.

Diante de tudo isso, o leitor sente-se desconfortável em meio a impossibilidade de identificar-se, tranquilamente, com o ponto de vista de que o leitor precisa adotar um tipo de leitura para conseguir ler. Sendo assim, é possível compreender que a literatura experimental de Veronica Stigger (2010a) só pode ser lida desde que se pense "fora de si”, como sugerem Natalia Brizuela (2014), Florência Garramuño (2009). De certo modo sim. Ao transitar em meio a imagens e movimentos, o trabalho da autora gaúcha faz com que se reveja o conceito de arte e também o lugar privilegiado ocupado pelo leitor, que é golpeado com um "soco no estômago" o tempo todo.

Portanto, Stigger (2010a) vai delineando corpos estranhos, assim como o livro, um objeto fora dos padrões estéticos. Aqui, o corpo em seu movimento de performance usa o espaço como uma tática de ocupação. Aguilar e Cámara (2017, p. 19) afirmam que uma cultura pode definir-se pela distribuição dos espaços. O uso artístico ou cultural que se faz deles implica uma ação de cunho político, que tem como fimm conservar, reforçar, subverter, modificar ou suprimir. "O corpo como um lugar político. O poder já não é algo exterior aos corpos, mas os atravessa com seus dispositivos". (AGUILAR; CÁMARA, 2017, p. 30).

É certo que Veronica Stigger fez de Os anões um livro-corpo, um movimento entre linguagem, estética e política que fez o leitor questionar-se sobre o que era a arte em meados do século XIX e XX. Atualmente, o leitor passa se perguntar quando se trata de uma obra de arte. A violência, as piadas, os absurdos, as colagens e citações que se movimentam livremente no espaço do livro, real e ficcional, fazem parte do ponto de fratura, do experimentar-se, do movimentar-se sempre aberto a múltiplas temporalidades.

\section{A encenação de uma viagem poético experimental}


Opisanie Swiata, ou a descoberta do mundo, de Verônica Stigger, publicado em 2013 pela extinta Cosac Naify, sugere uma experiência em um experimento poético narrativo. Ao manusear o livro, o leitor se coloca diante de um objeto extremamente sedutor composto por cartas geográficas, fotografias, cartões postais, anúncios publicitários, cardápio de restaurante, cartas pessoais e uma narrativa carregada de referências a personagens, autores e obras do modernismo brasileiro numa viagem da Polônia à Amazônia. Quem conduz a viagem é uma figura que traz o mesmo sobrenome de um artista visual de nacionalidade polonesa, Opalka, na narrativa de Stigger, um pai que descobre a existência de um filho no leito de morte e vai ao seu encontro até Amazônia, nas artes visuais, conhecido pelo projeto sobre "Contar o tempo", iniciado em 1965 e desenvolvido até sua morte, em 2011; acompanhado de Bopp, outro sobrenome que associamos a antropofagia do modernismo brasileiro e ao seu Cobra Norato.

Diante de tal objeto, se fixarmos o nosso olhar sobre como o assim autodenominado romance é construído, notamos que há um diálogo com as concepções já experimentadas pela vanguarda brasileira e europeia, em especial a ideia de ready-made, e outros autores e trabalhos mais recentes, como Valêncio Xavier de Mez da grippe, como já anuncia Flora Sussekind na orelha do livro.

Se Garramuño (2009) se afasta de um movimento genealógico de ver quando a literatura pode ser pensada fora de si e repete a marca temporal de Rosalind Krauss (1979), os anos 1960, Brizuela (2014) faz uma diferenciação entre o experimentalismo da metade do século com o que ocorre no início do século XX. Para ela,

As vanguardas históricas, em sua busca de uma ação direta (e muitas vezes revolucionária) sobre o mundo, propuseram uma síntese das artes - pensemos nas coloborações entre, por exemplo, Xul Solar, Jorge Luis Borges e Horacio Coppola, ou a integração de etnografia, musicologia, artes plásticas e literatura de Mário de Andrade [...] - um modelo de integração de diferentes disciplinas, todas em busca de uma cooperação que levasse a arte para o mundo, para a experiência e para a vida. A ideia por trás desses cruzamentos da primeira metade do século XX surge como variações da ideia de "obra de arte total [...] Creio que essas obras, as produzidas a partir da metade de 1950, não buscam uma síntese, mas uma abertura, também, como grande parte da produção literária das vanguardas, para tentar sair do encerramento da obra para o mundo. (BRIZUELA, 2014, p.84)

Ao tomarmos a consideração de Brizuela (2014), temos uma explicação das conclusões a que chega Angela Dias (2015), em “A descrição do mundo de Verônica Stigger 
ou uma antropofagia desidratada", sobre o experimentalismo de Verônica: "se apropria de uma comicidade leve e piadista, além da composição partida, sintética e descontínua" (DIAS, 2015, p.62). Assim, a inserção de elementos e referências ausentam-se de uma espécie de crítica que a antropofagia de um Bopp e de um Oswald traziam para o modernismo brasileiro para dar lugar a "antropofagia desidratada". As considerações de Dias (2011) são exemplificações das diferenças operadas pelas experienciações dos experimentos estéticos nestes dois momentos.

O desnudamento do processo de composição não é absolutamente um procedimento original. Desde o alto modernismo, a autoconsciência da forma constitui um padrão instituído de apropriação crítica do fazer criativo. No entanto, aqui, como gostaria de demonstrar, o recurso metacrítico não aposta em qualquer ponto de fuga reflexivo, mas ocupa-se prioritariamente com a sua economia interna, no sentido de satisfazer-se com o cultivo da engenhosidade que lhe é própria. (DIAS, 2015, p.64)

Quando nos detemos pontualmente na narrativa de Opisanie, observamos, por exemplo, que os personagens que atravessam o oceano são apresentados apenas pelo sobrenome, como nos lembra a própria Sttiger (2017) em entrevista a Manuel da Costa Pinto, é divertido como algumas críticas acadêmicas colocam como personagem Raul Bopp e Roman Opalka, em nenhum momento o primeiro nome aparece no corpo do texto. Neste sentido, a narrativa se monta não como um jogo de pistas falsas, ela se monta pela retirada do valor original do personagem histórico, atribuindo-lhe uma função a ser construída, o do personagem que encena uma ficção. Ou seja, Opalka e Bopp são esvaziados da carga e do repertório que esses dois nomes podem ter para as artes e a literatura e a tentativa, que cabe ao leitor, é colocá-los em cenas sucessivas em uma outra história que pode ser apenas uma encenação da linguagem.

A engenhosidade própria de Opisanie também é mencionada por Raquel Bueno, em "Opisanie Swiata: uma viagem contemporânea ao primeiro modernismo brasileiro" (2015). Nele, a autora, tomando como ponto de partida a ideia de literatura exigente, de Leila Perrone-Moysés, qual seja, de que há na produção literária contemporânea alguns textos que exigem "leitura atenta, releitura, reflexão e uma bagagem razoável de cultura, alta e pop para partilhar as referências explícitas e implícitas", muitos deles compostos de "obras de gênero inclassificável, misto de ficção, diário, ensaio, crônica e poesia” (apud BUENO, 2015, p.2).

O livro de Stigger estaria nesse conjunto de produção porque exigiria do leitor um repertório cultural, é a conclusão final de Bueno (2015, p.10): 
Ao final da leitura, prevalece a sensação de que um vasto arsenal de referências, sobretudo as que têm a ver com o tema da viagem na literatura brasileira do primeiro modernismo, contribuiu para uma narrativa engenhosa, que tem a cara deste fragmentado início de século XXI, mas que, talvez por isso mesmo, é incapaz de atualizar de forma mais produtiva técnicas e conteúdos de outras épocas. É uma escrita sem muitos problemas para resolver que aposta no lúdico menos para questionar do que para jogar o jogo do contemporâneo.

A recorrência ao lúdico que permeia o livro de Stigger, apontada pelas duas análises, encontra lugares confortáveis para se instalar, na seção "Deveres" e nos recortes que acompanham a narrativa. No primeiro, a autora lista todas as "fontes" que utilizou para compor o livro: encontramos aí as mais "seguras", como referências bibliográficas, filmes, mescladas com indicações de conversas com familiares, observações de conversas de rua, e num jogo de metalinguagem o próprio livro de Roman Opalka, agora assim nomeado, Opisanie Swiata. No segundo, traz cartas trocadas entre o médico, Natanael e Opalka, postais, frases que parecem ser colhidas na rua, anúncios publicitários. Esses elementos dão conta de marcar o tempo da narrativa, alertar sobre a vida nos trópicos, os hábitos, costumes e consumos de uma época, e apontar uma dramaticidade deslocada. Por exemplo, nas páginas que correspondem da 58 a 62, já que essas páginas não possuem numeração, vamos encontrar a sequência: carta de Opalka a Natanael, anunciando sua partida para o Brasil; em seguida a recomendação, "não há necessidade de levar armas de qualquer tipo. Nem mesmo as de fogo. Aliás, convém evita-las"; logo após, 3 páginas descrevendo o perfil do personagem Bopp como um viajante aventureiro e um pouco atrapalhado e, antes que volte para a narrativa da viagem, há um anúncio publicitário da Cia Nach Sudamerika.

O lúdico está no efeito da inserção dos recortes que montam situações paralelas: o trivial é tão necessário, ou desnecessário, para montar o romance quanto a dramaticidade do encontro com o filho à beira da morte.

Gustavo Ramos da Silva (2016), em dissertação intitulada Depois do fim do mundo: a Opisanie Swiata de Verônica Stigger, ao focar na narrativa de viagem vai nos dizer que:

[...] a viagem é feita de modo que, mais do que um deslocamento no espaço e no tempo dos personagens, o próprio leitor possa se colocar à prova e aceitar o convite para entrar no navio e na história que está para ser narrada; assim, à medida que avançamos na leitura, podemos sair dele diferentes de quando demos início à experiência da viagem. 
Silva (2016) enfatiza o lugar do leitor, no entanto, essa experiência tem um narrador que vê, observa com os minimos detalhes, anota, recolhe, reúne, distribui ao longo das páginas os fatos ocorridos. É um narrador descritivo, que não se espanta, não se comove, não se incomoda, não sente desconforto mesmo diante de situações absurdas. Joga com o leitor, que fica diante de um narrativa fora de si, tomando o termo de Garramuño (2009) e Brizuela (2014).

\section{Inconclusões Finais}

Seguindo os estudos de Krauss (1979), observamos que os críticos latino-americanos propõe uma investigação de criações artísticas que indicam momentos de transformação e possibilidades exploratórias de pensar o literário, pois há em algumas produções contemporâneas a deliberada corrosão de fronteiras e limites entre as formas de expressão e os suportes de composição por parte de artistas, o que delimita um espaço de não pertencimento. Esse espaço termina no momento em que se cria uma identidade do inespecífico ou de uma arte que se nega a ser confinada em um único jogo de regras e enunciados, passando a ocupar novos lugares, seja do ponto de vista estético quanto discursivo.

Em Os anões (2010a) e Opisanie Swiata (2013) não se pode ignorar a relação da história, da estética e da política com o experimentalismo. Ao pensar nessa literatura sem fronteiras, inespecífica, fora de si, assume-se a categoria de prática artística, conforme explica Brizuela (2014, p. 13-14). "Nessa zona porosa do limite, da fronteira, espaço e momento sempre de contágio, de contaminação e de metamorfose, tanto a literatura se transforma em outras artes, como as demais artes são potencialmente abolidas”.

Assim, vemos nessas criações o que chamamos que uma "encenação da linguagem", na qual gênero, autoria e leitor são colocados em jogo para movimentar o campo literário. Se Stigger toma o ready-made, ou mesmo a cópia, como maneira de construir seu trabalho artístico, teremos então que perceber que há nele uma espécie de crítica ao que constitui a literatura: tomar de empréstimo e não devolver, assumir-se seu, fazer cópias literais, tomar nomes e personagens e desprovi-los do seu lugar são alguns dos caminhos expansivos de Veronica Stigger. 


\section{Referências}

AGUILAR, Gonzalo; CÁMARA, Mario. A máquina performática: a literatura no campo experimental. Tradução de Gênese Andrade. Rio de Janeiro: Rocco (Entrecríticas), 2017.

ALVES, Wanderlan. Por uma ética dos afetos: Os anões, de Veronica Stigger. Revista Letras. V.28, n.57, p.11-28. Santa Maria, 2018. Disponível em: file://C:/Users/Rafael/Downloads/31868-170577-1-PB\%20(1).pdf. Acesso em: 03 jul. 2019.

BRIZUELA, Natalia. Depois da fotografia: uma literatura fora de si. $1^{\circ}$ edição. Rio de Janeiro: Rocco, 2014.

BUENO, Raquel Ilescas. Opisanie Swiata: uma viagem contemporânea ao primeiro modernismo brasileiro. Anais...XIV Congresso da Associação Brasileira de Literatura Comparada, Belém - Pará, 2015, p.1-11.

DIAS, Angela M. A descrição do mundo de Verônica Stigger ou uma antropofagia desidratada. O eixo e a roda, v.24, n. 1, p. 61-76. Belo Horizonte, 2015.

DIDI-HUBERMAN, Georges. A pintura encarnada. Trad. Osvaldo Fontes Filho e Leila de Aguiar Costa. São Paulo: Escuta, 2012.

GARRAMUÑO, Florência. La literatura en un campo expansivo: y la indisciplina del comparatismo. Cadernos de estudos culturais, Campo Grande, UFMS, v.1, n.2, p.101-111, 2009.

. Uma literatura fora de si. In: Frutos estranhos - sobre a inespecificidade na estética contemporânea. Tradução Carlos Nougué. Rio de Janeiro: Rocco, 2014, p. 31-48.

KLINGER, Diana. Escrita de si como performance. Revista brasileira de literatura comparada. n.12, p. 11-30, 2008.

KRAUSS, Rosalind. Escultura no campo ampliado. Revista Arteversa Ufrgs, maio 2015. Disponível em: <https://www.ufrgs.br/arteversa/?p=240>. Acesso em: 26 abr.2019.

. A escultura no campo ampliado. Gávea. Revista do Curso de especialização em História da Arte e Arquitetura no Brasil da PUC-Rio, n.I, p.128-137, 1984. Disponível em: $<$ https://monoskop.org/images/b/bc/Krauss_Rosalind_1979_2008_A_escultura_no_campo_a mpliado.pdf>. Acesso em: 08 jul. 2019.

. Sculpture in the Expanded Field. October 8, New York, (spring) 1979.

SILVA, Gustavo Ramos da. Depois do fim do mundo: a Opisanie Swiata de Veronica Stigger. Dissertação de mestrado. Programa de pós-graduação em Literatura. Universidade Federal de Santa Catarina, 2016.

SILVA, Damásio Marques da. Os anões: o papel do leitor na literatura de Veronica Stigger. Versalete. vol. 5, n.9, p.163-183, julho-dezembro 2017. 
SOUZA, Gustavo Ramos de. O espetáculo em minicontos de Os anões, de Veronica Stigger. Revista Virtual de Letras. v.08, ${ }^{\circ} 02,2016$. Disponível em:

$<$ https://www.academia.edu/31602431/O_ESPET\%C3\%81CULO_EM_MINICONTOS_DE_ OS_AN\%C3\%95ES_DE_VERONICA_STIGGER_THE_SPECTACLE_IN_FLASH_FICTI ONS_OF_OS_AN\%C3\%95ES_BY_VERONICA_STIGGER >. Acesso em: 11 jul. 2019.

STIGGER, Veronica. Entrevista concedida a Manuel da Costa Pinto. Segundas intenções Veronica Stigger. 30 de setembro de 2017. Disponível em: <

https://www.youtube.com/watch?v=f-Y3YdVcb6g>. Acesso em: 20 set. 2019.

. Opisanie swiata. São Paulo: Cosac Naify, 2013.

. Os anões. São Paulo: Cosac Naify, 2010a.

. "Gosto de provocar no leitor uma certa sensação de estranhamento", diz Veronica Stigger. Matéria publicada pela Folha UOL. 2010b. Entrevista concedida a Paula Dume. Disponível em:

$<$ https://www1.folha.uol.com.br/folha/livrariadafolha/767234-gosto-de-provocar-no-leitor-um a-certa-sensacao-de-estranhamento-diz-veronica-stigger.shtml $>$. Acesso em: 02 jul. 2019.

Recebido em 30/09/2019. Aceito em 04/12/2019. 